\title{
Possible mechanism underlying the association between height and vascular remodeling in elderly Japanese men
}

\author{
Yuji Shimizu'1,2, Shimpei Sato ${ }^{1}$, Jun Koyamatsu ${ }^{3}$, Hirotomo Yamanashi, Mako \\ Nagayoshi $^{1}$, Koichiro Kadota ${ }^{1}$, Shin-Ya Kawashiri ${ }^{1}$ and Takahiro Maeda ${ }^{1,3}$ \\ ${ }^{1}$ Department of Community Medicine, Nagasaki University Graduate School of Biomedical Science, Nagasaki, Japan \\ ${ }^{2}$ Department of Cardiovascular Disease Prevention, Osaka Center for Cancer and Cardiovascular Disease Prevention, Osaka, \\ Japan \\ ${ }^{3}$ Department of Island and Community Medicine, Nagasaki University Graduate School of Biomedical Science, Nagasaki, \\ Japan
}

Correspondence to: Yuji Shimizu, email: shimizuyuji@nagasaki-u.ac.jp

Keywords: platelets; height; vascular remodeling; CIMT; CD34-positive cell; Gerotarget

Received: September 29, 2017

Accepted: October 30, 2017

Published: December 23, 2017

Copyright: Shimizu et al. This is an open-access article distributed under the terms of the Creative Commons Attribution License 3.0 (CC BY 3.0), which permits unrestricted use, distribution, and reproduction in any medium, provided the original author and source are credited.

\section{ABSTRACT}

Height is reported to be inversely associated with cardiovascular disease. And platelets play an important role in vascular remodeling by supporting CD34-positive cells. To clarify the association between height and platelet, we conducted a crosssectional study of $\mathbf{2 1 9}$ elderly Japanese men. Since hemoglobin concentration is influenced by vascular remodeling activity, an analysis stratified by hemoglobin level was performed. An inverse association was seen between height and platelet count in subjects with a high hemoglobin concentration ( $\geq 14.5 \mathrm{~g} / \mathrm{dL})$, but not in subjects with a low hemoglobin concentration $(<14.5 \mathrm{~g} / \mathrm{dL})$. The standardized parameter estimates $(\beta)$ were $\beta=-0.22, p=0.019$ for subjects with high hemoglobin, and $\beta=-0.01, p=0.931$ for subjects with low hemoglobin. We also found a positive association between platelets and carotid intima media thickness (CIMT) and circulating CD34-positive cells in subjects with high hemoglobin (partial correlation coefficient $(r)=0.21, p=0.037$ and $r=0.40, p=<0.001)$, but not in subjects with low hemoglobin $(r=0.04, p=0.710$ and $r=0.06, p=0.544)$. In subjects with a high hemoglobin concentration, platelets were inversely associated with height, and positively associated with CIMT and circulating CD34-positive cells. These results indicate that subjects with a short stature activate vascular remodeling to a much greater extent than subjects with a tall stature.

\section{INTRODUCTION}

Height is reported to be inversely associated with incidence of cardiovascular disease [1]. Our previous study of Japanese men revealed an inverse association between height and carotid atherosclerosis among overweight subjects, but not in those who were not overweight [2]. Atherosclerosis is known to be a chronic inflammatory disease [3], and a higher white blood cell count has also been identified as a marker of systemic inflammatory activity that is known to be associated with atherosclerosis [4]. In connection with these phenomena, we also reported that short stature is associated with inflammatory disadvantages since high white blood cell count is inversely associated with height in subjects with a body mass index $(\mathrm{BMI}) \geq 23 \mathrm{~kg} / \mathrm{m}^{2}$ but not in those with a BMI $<23 \mathrm{~kg} / \mathrm{m}^{2}$ [5]. Additionally, an Asian-specific inflammation-related single nucleotide polymorphism (SNP) (rs3782886) was also revealed to be significantly associated with short stature [6]. These studies indicate that short stature is associated with vascular pathological disadvantages.

On the other hand, a growing body of evidence indicates that platelets play an important role in inflammation [7], and are also reported to be important in the development of atherosclerotic lesions as an initial actor [8]. Platelets promoted the mobilization of bone marrow-derived CD34-positive cells into the peripheral 
blood [9]. Furthermore, platelets not only induce differentiation of CD34-positive cells into endothelial progenitor cells and endothelial cells, but also into foam cells $[10,11]$ which is a well-known contributing factor in the development of atherosclerotic lesions.

Since the development of atherosclerosis is one aspect of vascular repair, and we previously reported that platelet count indicates the activity of vascular repair (endothelial repair and development of atherosclerosis) [12], studies clarifying the association between height and platelet count and its association with circulating CD34positive cells might be an efficient tool to evaluate the risk of vascular pathological disadvantages caused by short stature.

In addition to the above, bone metabolism is known to be associated with vascular maintenance [13], and age-related reduction in bone marrow activity is known to cause anemia in the elderly [14]. Additionally, hypertension is a strong endothelial impairment factor, and hemoglobin is known to be positively associated with hypertension [15], atherosclerosis [16], and hypertensioninduced vascular damage [17]. Therefore, subjects with low hemoglobin concentration should demonstrate lower vascular maintenance activity, while subjects with a high hemoglobin concentration should show higher activity. Since the aim of our present study was to evaluate the influence of height on activated vascular repair (platelet levels) in elderly men, we conducted a cross-sectional study stratified by hemoglobin level of elderly Japanese men aged 65-69 years who participated in a general health check-up from 2013-2015.

\section{RESULTS}

\section{Characteristics of study population}

A simple correlation analysis found no significant correlation between height and age; $r=-0.11(p=0.093)$. Among 219 subjects, 115 presented with low hemoglobin concentration $(\mathrm{Hb}<14.5 \mathrm{~g} / \mathrm{dL})$ and 104 with high hemoglobin concentration $(\mathrm{Hb} \geq 14.5 \mathrm{~g} / \mathrm{dL})$.

Characteristics of the study population based on hemoglobin status are shown in Table 1. Compared to those with low hemoglobin, high hemoglobin subjects demonstrated significantly higher values for reticulocytes, white blood cells, systolic and diastolic blood pressure, and body mass index.

\section{Correlation analysis of hematological parameters, carotid intima media thickness (CIMT), and height}

Table 2 shows a correlation analysis of hematological parameters, CIMT, and height. For subjects with high hemoglobin, platelets were significantly positively associated with CIMT, circulating CD34- positive cells and white blood cells, and inversely associated with height. We also found a significant positive association between reticulocytes and white blood cells and height, but not CIMT

\section{Association between platelets and height}

From a simple correlation analysis, height was found to be significantly inversely associated with platelets in subjects with high hemoglobin but not in subjects with low hemoglobin (Table 3).

Scatter plot data indicated a significant inverse association between platelets and height and a significant positive association between platelets and circulating CD34-positive cells in subjects with high hemoglobin but not in subjects with low hemoglobin (Figure 1).

These associations remained unchanged even after further adjustment for known cardiovascular risk factors (Table 4).

\section{DISCUSSION}

The major findings of the present study are a significant inverse association between platelet count and height, and a significant positive association between platelet count and circulating CD34-positive cells and CIMT in subjects with high hemoglobin concentration. No such significant associations were present in subjects with low hemoglobin concentration.

In a previous study, we reported an inverse association between height and high white blood cell count in those with a BMI $\geq 23 \mathrm{~kg} / \mathrm{m}^{2}$ but not with a BMI $<23 \mathrm{~kg} / \mathrm{m}^{2}$ [5]. Since a high white blood cell count, which indicates elevated inflammatory activity, is significantly positively associated with atherosclerosis [4], height may be inversely associated with this disease. In fact, our previous study of Japanese men revealed an inverse association between height and carotid atherosclerosis in overweight (BMI $\geq 25 \mathrm{~kg} / \mathrm{m}^{2}$ ), but not non-overweight $\left(\mathrm{BMI}<25 \mathrm{~kg} / \mathrm{m}^{2}\right)$ subjects [2]. In the present study, to evaluate the influence of height on progressive vascular remodeling, further analyses showed no-significant association between height and CIMT for subjects with both high and low hemoglobin; fully-adjusted standardized parameter estimates $(\beta)$ and $p$-values were $\beta=-0.001, p$ $=0.992$ for subjects with high hemoglobin and $\beta=0.11$, $p=0.290$ for subjects with low hemoglobin. Since our present study population comprised individuals within the normal BMI range $\left(18.5-24.9 \mathrm{~kg} / \mathrm{m}^{2}\right)$ our present results are compatible with those of previous studies we conducted [2, 5]. However, atherosclerosis (increased CIMT) is only one aspect of vascular repair (aggressive endothelial repair). Therefore, compared to subjects with a tall stature, subjects with a short stature may show much stronger vascular repair activity (appropriate endothelial repair) even within the normal BMI range. 
Table 1: Characteristics of the study population based on hemoglobin levels

\begin{tabular}{|c|c|c|c|}
\hline & $\begin{array}{c}\text { Low hemoglobin } \\
\mathrm{Hb}<14.5 \mathrm{~g} / \mathrm{dL}\end{array}$ & $\begin{array}{c}\text { High hemoglobin } \\
\mathrm{Hb} \geq 14.5 \mathrm{~g} / \mathrm{dL}\end{array}$ & $p$ value \\
\hline No. of participants & 115 & 104 & \\
\hline Age, years & $67.2 \pm 1.2$ & $67.5 \pm 1.3$ & 0.103 \\
\hline Reticulocytes, \%o & $10.4 \pm 3.5$ & $12.3 \pm 3.5$ & $<0.001$ \\
\hline Circulating CD34 positive cells, cells $/ \mu \mathrm{L}$ & $1.17 \pm 1.92$ & $1.36 \pm 1.36$ & 0.419 \\
\hline White blood cells, cells $/ \mu \mathrm{L}$ & $5161 \pm 1316$ & $5869 \pm 1368$ & $<0.001$ \\
\hline Platelets, $\times 10^{4} / \mu \mathrm{L}$ & $22.2 \pm 6.3$ & $21.4 \pm 4.9$ & 0.302 \\
\hline Mean carotid intima media thickness (CIMT), mm & $0.69 \pm 0.11$ & $0.71 \pm 0.12$ & 0.154 \\
\hline Systolic blood pressure, $\mathrm{mmHg}$ & $130 \pm 18$ & $137 \pm 16$ & 0.004 \\
\hline Diastolic blood pressure, $\mathrm{mmHg}$ & $76 \pm 12$ & $82 \pm 10$ & $<0.001$ \\
\hline Body mass index (BMI), $\mathrm{kg} / \mathrm{m}^{2}$ & $21.9 \pm 1.8$ & $22.5 \pm 1.8$ & 0.021 \\
\hline Serum HDL-cholesterol (HDL), mg/dL & $58 \pm 14$ & $57 \pm 13$ & 0.695 \\
\hline Serum triglycerides, mg/dL & $113 \pm 110$ & $111 \pm 49$ & 0.869 \\
\hline Hemoglobin A1c (HbA1c), \% & $5.6 \pm 0.5$ & $5.8 \pm 0.7$ & 0.149 \\
\hline Serum aspartate aminotransferase (AST), IU/L & $24 \pm 7$ & $26 \pm 10$ & 0.144 \\
\hline Serum $\gamma$-glutamyltranspeptidase ( $\gamma$-GTP), IU/L & $41 \pm 34$ & $48 \pm 47$ & 0.179 \\
\hline Serum creatinine, $\mathrm{mg} / \mathrm{dL}$ & $0.85 \pm 0.16$ & $0.82 \pm 0.15$ & 0.306 \\
\hline Height, $\mathrm{cm}$ & $164.2 \pm 5.0$ & $163.8 \pm 6.2$ & 0.563 \\
\hline
\end{tabular}

Age: mean \pm standard deviation.

Endothelial dysfunction has been recognized as one of the initial mechanisms leading to atherosclerosis (increased arterial stiffness) [18]. Platelets are the first circulating blood cells that interact with an injured vessel (injured endothelium) [19]. Platelets usually do not interact with the intact vascular endothelium. Once the arterial endothelium becomes injured, subendothelial components such as collagen [20] and von Willebrand factor [21] are exposed, resulting in the adherence of platelets to the damaged vessel wall and their subsequent activation. Activated platelets (P-selectinpositive platelets) release stromal cell-derived factor-1 (SDF-1) [22]. And co-cultivation experiments showed that human platelets recruit CD34-positive cells via specific adhesion receptors P-selectin/PSGL-1 and beta1- and beta2-integrins. This study also reported that platelets induced differentiation of CD34-positive cells into mature endothelial cells and foam cells [11]. Another study reported that Platelet-derived SDF-1 regulates adhesion of stem cells in vitro and in vivo, and the differentiation of CD34-positive cells to endothelial progenitor cells [10].

Since bone marrow-derived endothelial cells such as CD34-positive stem cells support the integrity of the vascular endothelium [23], platelets play an important role in vascular repair not only by serving as "bridging cells" between endothelial progenitor cells and the injured arterial endothelium, but also by inducing the differentiation of CD34-positive cells.
Furthermore, platelet-rich plasma could enhance the proliferation of bone marrow mesenchymal stem cells, which are known to be multi-potent stem cells [24]; and we also previously reported that the number of platelets indicates the activity of vascular repair [12]. Platelets not only indicate vascular repair activity but the degree of endothelial injury as well. In the present study, the positive association between platelets and circulating CD34positive cells and CIMT of subjects with high hemoglobin might support the above-mentioned mechanism.

However, no such associations were found in subjects with a low hemoglobin level. Bone marrow activity decreases as individuals age [25], which may be associated with the increased frequency of anemia seen in the elderly [14], and bone metabolism is known to be associated with vascular maintenance [13]. In addition, hypertension is a strong endothelial impairment factor and hemoglobin has been revealed to be positively associated with hypertension [15], atherosclerosis [16], and hypertension-induced vascular damage [17]. Therefore, a weak vascular repair response is caused both by an age-related reduction in bone marrow activity and a small degree of vascular injury resulting in a low level of hemoglobin, which might act as a strong confounding factor on platelets as an indicator of vascular remodeling.

A summary of the possible mechanisms underlying the association between height and vascular remodeling (endothelial repair) is shown in Figure 2. Short stature 
Table 2: Correlation analysis of hematological parameters, carotid intima media thickness (CIMT) and height

\begin{tabular}{|c|c|c|c|c|c|c|}
\hline & Platelets & Reticulocytes & Mean CIMT & $\begin{array}{l}\text { Circulating CD34 } \\
\text { positive cells }\end{array}$ & White blood cells & Height \\
\hline \multicolumn{7}{|c|}{ Low hemoglobin $(\mathrm{Hb}<14.5 \mathrm{~g} / \mathrm{dL})$} \\
\hline \multicolumn{7}{|c|}{ Simple correlation analysis } \\
\hline Platelets & - & $0.16(0.090)$ & $-0.01(0.928)$ & $0.11(0.248)$ & $0.45(<0.001)$ & $-0.03(0.723)$ \\
\hline Reticulocytes & $0.16(0.090)$ & - & $0.002(0.985)$ & $0.002(0.985)$ & $0.15(0.107)$ & $0.03(0.722)$ \\
\hline Mean CIMT & $-0.01(0.928)$ & $0.002(0.985)$ & - & $0.08(0.373)$ & $-0.02(0.852)$ & $-0.03(0.753)$ \\
\hline \multicolumn{7}{|c|}{ Partial correlation analysis } \\
\hline Platelets & - & $0.18(0.070)$ & $0.04(0.710)$ & $0.06(0.544)$ & $0.44(<0.001)$ & $-0.06(0.515)$ \\
\hline Reticulocytes & $0.18(0.070)$ & - & $0.03(0.735)$ & $0.002(0.981)$ & $0.16(0.100)$ & $0.02(0.836)$ \\
\hline Mean CIMT & $0.04(0.710)$ & $0.03(0.735)$ & - & $0.07(0.497)$ & $0.06(0.516)$ & $-0.01(0.925)$ \\
\hline \multicolumn{7}{|c|}{ High hemoglobin $(\mathrm{Hb} \geq 14.5 \mathrm{~g} / \mathrm{dL})$} \\
\hline \multicolumn{7}{|c|}{ Simple correlation analysis } \\
\hline Platelets & - & $0.13(0.179)$ & $0.23(0.017)$ & $0.35(<0.001)$ & $0.36(<0.001)$ & $-0.25(0.010)$ \\
\hline Reticulocytes & $0.13(0.179)$ & - & $0.09(0.387)$ & $0.14(0.151)$ & $0.42(<0.001)$ & $0.28(0.004)$ \\
\hline Mean CIMT & $0.23(0.017)$ & $0.09(0.387)$ & - & $-0.02(0.815)$ & $0.28(0.004)$ & $0.06(0.552)$ \\
\hline \multicolumn{7}{|c|}{ Partial correlation analysis } \\
\hline Platelets & - & $0.08(0.466)$ & $0.21(0.037)$ & $0.40(<0.001)$ & $0.31(0.002)$ & $-0.24(0.018)$ \\
\hline Reticulocytes & $0.08(0.466)$ & - & $0.16(0.120)$ & $0.10(0.324)$ & $0.38(<0.001)$ & $0.37(<0.001)$ \\
\hline Mean CIMT & $0.21(0.037)$ & $0.16(0.120)$ & - & $-0.01(0.925)$ & $0.26(0.010)$ & $0.10(0.357)$ \\
\hline
\end{tabular}

CIMT: carotid intima media thickness. Partial correlation analysis is adjusted for age, SBP, BMI, triglycerides, HDL, AST, $\gamma$-GTP, HbA1C, and creatinine. Circulating CD34-positive cells, triglycerides, $\gamma$-GTP, and creatinine are calculated in logarithm values.

Table 3: Simple correlation coefficient of platelets and other variables

\begin{tabular}{|c|c|c|c|c|}
\hline & \multicolumn{2}{|c|}{$\begin{array}{c}\text { Low hemoglobin } \\
\mathrm{Hb}<14.5 \mathrm{~g} / \mathrm{dL} \\
\end{array}$} & \multicolumn{2}{|c|}{$\begin{array}{c}\text { High hemoglobin } \\
\mathrm{Hb} \geq 14.5 \mathrm{~g} / \mathrm{dL}\end{array}$} \\
\hline & $\mathbf{r}$ & $p$ & $\mathbf{r}$ & $p$ \\
\hline No. of participants & \multicolumn{2}{|c|}{115} & \multicolumn{2}{|c|}{104} \\
\hline Age & -0.16 & 0.098 & 0.01 & 0.934 \\
\hline Systolic blood pressure & 0.06 & 0.517 & 0.02 & 0.859 \\
\hline Body mass index (BMI) & 0.06 & 0.536 & -0.08 & 0.424 \\
\hline Serum HDL-cholesterol (HDL) & -0.08 & 0.378 & -0.08 & 0.395 \\
\hline Serum triglycerides & 0.02 & 0.873 & 0.09 & 0.376 \\
\hline Hemoglobin A1c (HbA1c) & -0.03 & 0.740 & 0.13 & 0.174 \\
\hline Serum aspartate aminotransferase (AST) & -0.26 & 0.006 & -0.15 & 0.142 \\
\hline Serum $\gamma$-glutamyltranspeptidase ( $\gamma$-GTP) & -0.16 & 0.079 & 0.16 & 0.101 \\
\hline Serum creatinine & -0.014 & 0.884 & -0.21 & 0.029 \\
\hline White blood cells (WBC) & 0.25 & 0.008 & 0.30 & 0.002 \\
\hline Height & -0.03 & 0.723 & -0.25 & 0.010 \\
\hline
\end{tabular}

r: simple correlation coefficient. Triglycerides, $\gamma$-GTP, and creatinine are calculated in logarithm values.

entails a higher risk of endothelial impairment [2] such as chronic inflammation $[5,6]$, which stimulates endothelial repair activity. Since endothelial activity is closely associated with bone marrow activity [13, 23], which is also strongly influenced by age-related decline $[14,25]$, an analysis limited to subjects with high bone marrow activity (high hemoglobin) should strengthen the influence of endothelial repair. However, although both 
Table 4: Multiple linear regression analysis of platelet with relevant factors adjusted for confounding factors

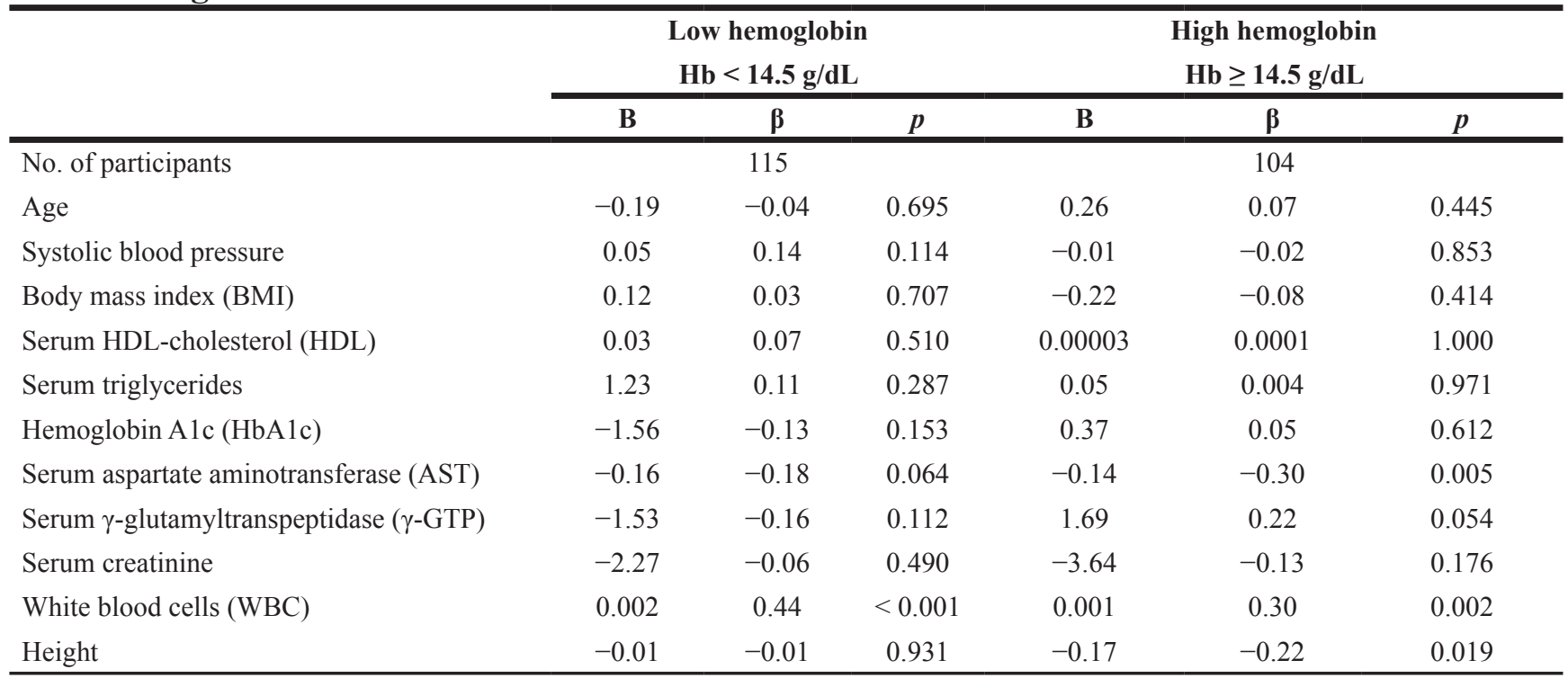

B: parameter estimate. $\beta$ : standardized parameter estimate. Triglycerides, $\gamma$-GTP, and creatinine are calculated in logarithm values.

platelet and CD34-positive cell production are stimulated by endothelial injury, aggressive endothelial repair (the cause of atherosclerosis) may cause consumptive reduction of CD34-positive cells, but not platelets [26]. Therefore, in the present study, among subjects with high hemoglobin, although a significant positive association

\section{Low hemoglobin}

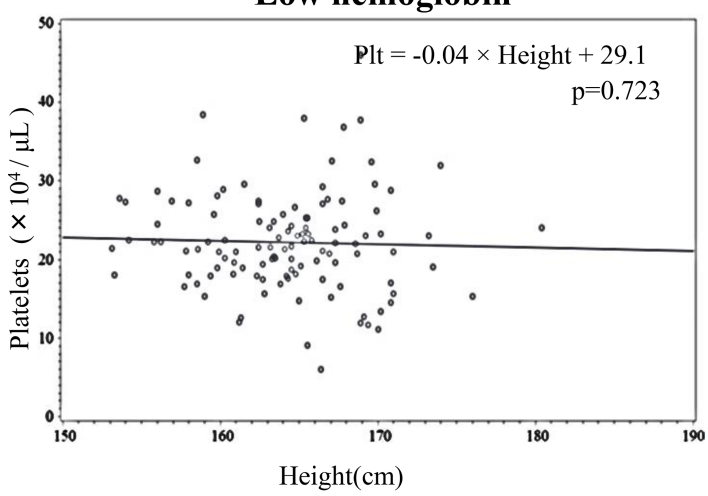

Low hemoglobin

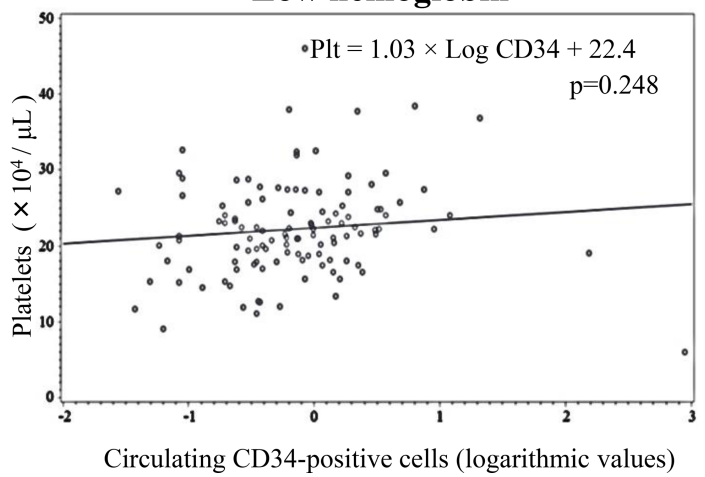

between platelets and CIMT was observed, there was no significant association between circulating CD34-positive cells and CIMT. In addition, as in our previous study [2], we found no significant association between height and CIMT. Additional studies we conducted previously reported that a high level of platelets and a low level of

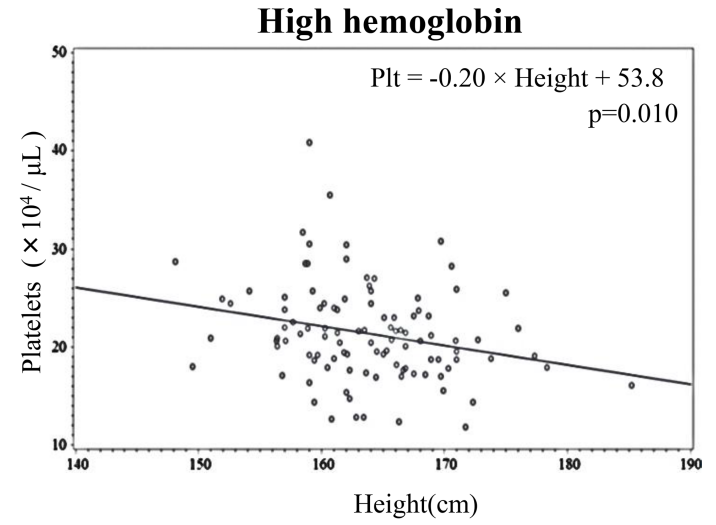

High hemoglobin

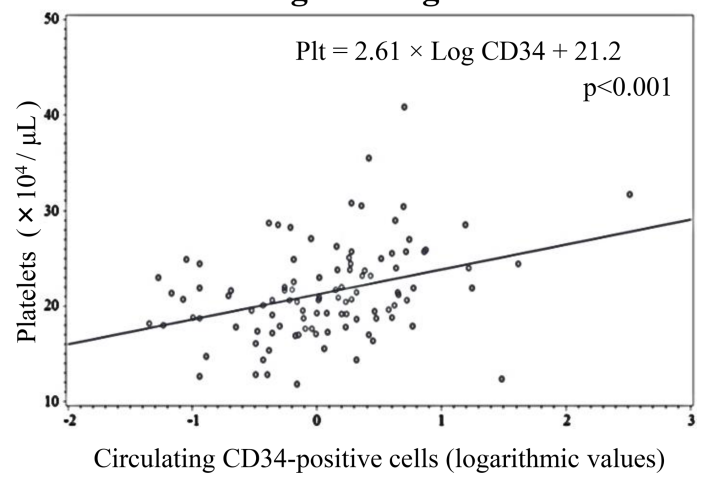

Figure 1: Scatter plot of platelets and height, and platelets and circulating CD34-positive cells. 
circulating CD34-positive cells is an independent risk factor for the vicious cycle between hypertension and atherosclerosis, whereas high platelets and high CD34positive cells are not since appropriate endothelial repair is established in these subjects [26]. In our present study, we found a significant positive association between platelets and circulating CD34-positive cells among subjects with high hemoglobin levels. The majority of these subjects with high hemoglobin may therefore activate endothelial repair activity and establish appropriate endothelial repair, resulting in no significant association between height and CIMT. Further investigations with a larger number of subjects with high hemoglobin and circulating CD34positive cell data that enables us to perform circulating CD34-positive cell level-specific analysis will be necessary. In addition to these mechanisms, in our present study, we found a significant positive association between height and reticulocytes among subjects with a high hemoglobin concentration, as shown in a previous study [27]. Since endothelial activity is strongly associated with bone marrow activity $[13,23]$ and reticulocytes act as an indicator of such activity, this positive association between height and reticulocytes may also partly indicate that subjects with a short stature might be at a disadvantage as a result of deficient endothelial repair.

In the present study, although the correlation between height and platelet count is small, short stature activates vascular remodeling more strongly than tall stature for following reasons. First, height is positively associated with vascular maintenance capacity [28]. If aggressive vascular repair is evoked by serious endothelial damage, the maximum ability of vascular repair should be defined by height - subjects with a short stature would not activate vascular repair as strongly as subjects with a tall stature (ceiling effect). Since short stature is associated with inflammatory disadvantages $[5,6]$, this type of ceiling effect should act as a strong confounding factor on the association between height and platelet count. We also previously reported that height is positively associated with hematopoietic capacity [27], and bone marrow stroma cells differentiate into megakaryocytes that subsequently produce platelets [29]. In the present study population, reticulocytes were found to be significantly positively associated with height. Therefore, hematopoietic capacity also should act as a strong confounding factor on the association between height and platelet count.

In previous study, a significant positive correlation was reported between height and number of circulating CD34-positve cells in subjects with systolic hypertension but not in those without, independent of known cardiovascular risk factors [28]. And we also reported in previous study that the number of platelets and circulating CD34-positive cells acts as an indicator of the activity of the vicious cycle that exists between hypertension and endothelial dysfunction in elderly Japanese men [26]. Since a significant inverse association was observed between height and platelet count among elderly Japanese men in present study, those with short stature might also activates the vicious cycle that exists between hypertension and endothelial dysfunction much

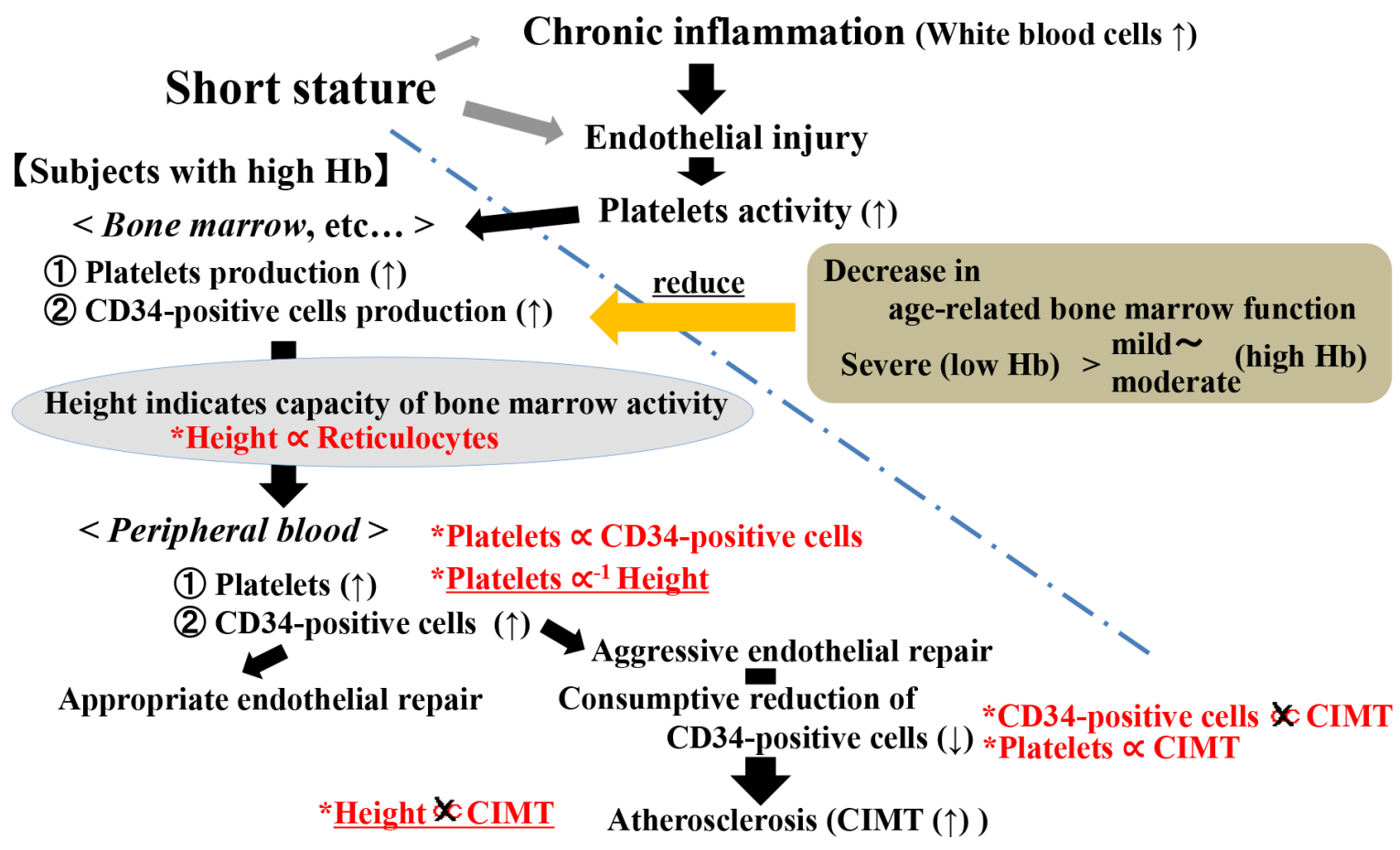

Figure 2: Possible mechanism underlying the association between height and vascular remodeling (endothelial repair). The mechanism below the dotted line is observed only for subjects without severe age-related bone marrow activity reduction (subjects with high $\mathrm{Hb}$ ). Relations in red were observed in the present analysis. Hb: hemoglobin. CIMT: carotid intima-media thickness. 
more strongly compared to those with a tall stature. Since hypertension, but not height, can be altered by improving living habits, it is necessary that subjects with a short stature control their daily blood pressure much more precisely compared to those with a tall stature.

Although our present study employs a small sample size, it is the largest study in the world that deals with circulating CD34-positive cells among the general elderly population who are selected in a strict manner-subjects were restricted to men in a narrow age and normal BMI range because gender differences, age and high BMI can act as strong confounding factors on the association between height and other variables [30-32].

Potential limitations of this study warrant consideration. Because creatinine clearance data were not available and estimated glomerular filtration rate (GFR) is not an effective tool for evaluating kidney function for a comparison of associations with various body heights $[1,2,5,27,28,32]$, we were not able to perform an analysis adjusted for exact renal function. However, our study showed that the association between height and platelet count remained significant even after adjustment for serum creatinine. Although significant associations exist between height and hematological parameters such as platelets and reticulocytes, no data was available with regard to the evaluation of endothelial function. Further analyses that include endothelial function-related data such as Flow Mediated Dilation (FMD) will be necessary. Additionally, because this was a cross-sectional study, causal relationships were not able to be established. However, since height was regarded as a surrogate marker of childhood social and physical condition $[1,2,5,6,27,28,32]$ and the target population in the present study was elderly men, we believe this investigation has the characteristics of a prospective study to a certain degree. Further prospective population based studies are needed to eliminate the possibility of a causal relationships.

In conclusion, a significant inverse association was observed between height and platelet count, while a significant positive association was seen between platelets and circulating CD34-positive cells and CIMT in subjects with a high hemoglobin concentration, but not in those with a low hemoglobin concentration. These results indicate that among elderly Japanese men, those with a short stature activate vascular remodeling much more strongly compared to those with a tall stature.

\section{MATERIALS AND METHODS}

\section{Ethics statement}

Participants in this study was essentially voluntary. Written consent forms were available in Japanese to ensure comprehensive understanding, and informed consent was given by all participants. This study was approved by the Ethics Committee for Human Use of Nagasaki University (projects registration number 14051404).

\section{Study populations}

To avoid the influence of age on height, this study was comprised of subjects in a narrow age range, as in a previous study that reported the influence of height among elderly subjects $[27,28]$. The original population included 409 men 65 to 69 years old residing in rural communities in Nagasaki Prefecture in western Japan. Participants were recruited from 2013-2015. To avoid the influence of inflammatory and hematological disease, subjects with high and low white blood cell counts $(\geq 10,000$ cells/ $\mu \mathrm{L}(n=2)$ and 1,000 cells $/ \mu \mathrm{L}<(n=1)$, respectively $)$ were excluded. Additionally, to avoid the influence of medication activating the bone marrow, subjects taking medication for anemia $(n=3)$ were also excluded.

Since hemoglobin value shows a strong positive correlation with body mass index $[15,16]$, and another study reported a J- or U-shaped correlation between BMI and mortality [33], abnormal BMI status might act as a strong confounding factor for the correlation between height and reticulocyte count. Therefore, to avoid the influence of undernutrition and hyper-nutrition, subjects with a BMI $<18.5 \mathrm{~kg} / \mathrm{m}^{2}(n=50)$ and $\mathrm{BMI} \geq 25 \mathrm{~kg} / \mathrm{m}^{2}$ $(n=103)$, respectively, were excluded. Subjects with no evaluable laboratory data $(n=1)$ and with no CD34positive cell count data available $(n=30)$ were also excluded, leaving a total of 219 subjects participating in the study.

\section{Data collection and laboratory measurements}

Trained interviewers obtained information on medical history. Body weight and height of patients wearing light clothing were measured using an automatic body composition analyzer (BF-220; Tanita, Tokyo, Japan), and BMI $\left(\mathrm{kg} / \mathrm{m}^{2}\right)$ was calculated. Fasting was defined as not taking breakfast. Fasting blood samples were collected in a heparin sodium tube, EDTA-2K tube and a siliconized tube. Fresh samples (within 24 hours from drawing) from the heparin sodium tube were used to determine the number of CD34-positive cells. BD (Beckton Dickinson Biosciences) Trucount ${ }^{\mathrm{TM}}$ technology, an accurate and reproducible single platform assay cited in the International Society of Hematotherapy and Graft Engineering (ISHAGE) guidelines [34] and supported by automated software on the BD FACSCant ${ }^{\mathrm{TM}}$ II system, was used to measure circulating CD34-positive cells.

Samples from the EDTA-2K tube were used to measure white blood cell count, platelet count and reticulocytes using automated procedure at SRL, Inc. (Tokyo, Japan). Serum triglycerides, serum high 
density lipoprotein (HDL) cholesterol, serum aspartate aminotransferase (AST), serum $\gamma$-glutamyltranspeptidase $\left(\gamma\right.$-GTP), hemoglobin A1c $\left(\mathrm{HbA}_{1 \mathrm{C}}\right)$, and serum creatinine were measured using standard laboratory procedures at SRL, Inc. (Tokyo, Japan).

Measurement of CIMT by ultrasonography of the left and right carotid arteries was performed by an experienced vascular technician using a LOGIQ Book XP with a $10-\mathrm{MHz}$ transducer, GE Healthcare, Milwaukee, WI, USA). Mean values for the left and right CIMT were calculated using automated digital edge-detection software (Intimascope; MediaCross, Tokyo, Japan), with the protocol described in detail elsewhere [35].

\section{Statistical analysis}

Characteristics of the study population stratified by hemoglobin levels were expressed as mean \pm standard deviation. Simple and partial correlation analysis (Pearson) adjusted for known cardiovascular risk factors were performed to evaluate hematological parameters, CIMT and height. Simple correlation coefficients of platelets and other variables were calculated. Multiple linear regression analyses were also performed to evaluate the same. Since inter-correlation with systolic blood pressure was $r=0.72(P<0.001)$, diastolic blood pressure was not analyzed as a confounding factor. Because circulating CD34-positive cells, triglycerides, $\gamma$-GTP, and serum creatinine had a skewed distribution, logarithmic transformation was performed for the simple and partial correlation analysis, and linear regression analysis. All statistical analyses were performed with the SAS system for Windows (version 9.4; SAS Inc., Cary, NC). Probability values of less than 0.05 were considered to be statistically significant.

\section{Author contributions}

YS designed the study and performed the statistical analyses, interpreted the data, and drafted the manuscript or revised it. $\mathrm{MN}, \mathrm{KK}, \mathrm{SS}$ and $\mathrm{JK}$ assisted with the design of the study, were involved in data collection, and checked the manuscript. SY.K, JK, and HY participated in the study concept and checked the manuscript. TM was the general coordinator and also designed the study.

\section{ACKNOWLEDGMENTS}

We are grateful to the staff of Goto city office and Saza town office for their outstanding support.

\section{CONFLICTS OF INTEREST}

The authors declare that they have no conflicts of interest.

\section{FUNDING}

This study was supported by Grants-in-Aids for Scientific Research from the Japan Society for the Promotion of Sciences (No.15K07243, No.17H03740, No. 25291107)

\section{REFERENCES}

1. Shimizu Y, Imano H, Ohira T, Kitamura A, Kiyama M, Okada T, Ishikawa Y, Shimamoto T, Yamagishi K, Tanigawa T, Iso H. CIRCS Investigators. Adult height and body mass index in relation to risk of total stroke and its subtypes: the circulatory risk in communities study. J Stroke Cerebrovasc Dis. 2014; 23:667-674.

2. Shimizu Y, Nakazato M, Sekita T, Kadota K, Arima K, Yamasaki H, Goto H, Shirahama S, Takamura N, Aoyagi K, Maeda T. Relationship between adult height and body weight and risk of carotid atherosclerosis assessed in terms of carotid intima-media thickness: the Nagasaki Islands study. J Physiol Anthropol. 2013; 32:19.

3. Lusis AJ. Atherosclerosis. Nature. 2000; 407:233-241.

4. Ortega E, Gilabert R, Nuñez I, Cofán M, Sala-Vila A, de Groot E, Ros E. White blood cell count is associated with carotid and femoral atherosclerosis. Atherosclerosis. 2012; 221:275-281.

5. Shimizu Y, Yoshimine H, Nagayoshi M, Kadota K, Takahashi K, Izumino K, Inoue K, Maeda T. Short stature is an inflammatory disadvantage among middle-aged Japanese men. Environ Health Prev Med. 2016; 21:361-367.

6. Shimizu Y, Sato S, Noguchi Y, Koyamatsu J, Yamanashi H, Higashi M, Nagayoshi M, Kadota K, Kawashiri SY, Nagata Y, Takamura N, Maeda T. Impact of single nucleotide polymorphism on short stature and reduced tongue pressure among community-dwelling elderly Japanese participants: a cross-sectional study. Environ Health Prev Med. 2017; 22:62.

7. Gawaz M, Langer H, May AE. Platelets in inflammation and atherogenesis. J Clin Invest. 2005; 115:3378-3384.

8. Lindemann S, Krämer B, Seizer P, Gawaz M. Platelets, inflammation and atherosclerosis. J Thromb Haemost. 2007; 5:203-211.

9. Stellos K, Bigalke B, Langer H, Geisler T, Schad A, Kögel A, Pfaff F, Stakos D, Seizer P, Müller I, Htun P, Lindemann S, Gawaz M. Expression of stromal-cell-derived factor-1 on circulating platelets is increased in patients with acute coronary syndrome and correlates with the number of CD34+ progenitor cells. Eur Heart J. 2009; 30:584-593.

10. Stellos K, Langer H, Daub K, Schoenberger T, Gauss A, Geisler T, Bigalke B, Mueller I, Schumm M, Schaefer I, Seizer P, Kraemer BF, Siegel-Axel D, et al. Plateletderived stromal cell-derived factor-1 regulates adhesion and promotes differentiation of human CD34+ cells to endothelial progenitor cells. Circulation. 2008; 117:206-215. 
11. Daub K, Langer H, Seizer P, Stellos K, May AE, Goyal P, Bigalke B, Schönberger T, Geisler T, Siegel-Axel D, Oostendorp RA, Lindemann S, Gawaz M. Platelets induce differentiation of human $\mathrm{CD} 34+$ progenitor cells into foam cells and endothelial cells. FASEB J. 2006; 20:2559-2261.

12. Shimizu Y, Sato S, Koyamatsu J, Yamanashi H, Nagayoshi M, Kadota K, Maeda T. Platelets as an indicator of vascular repair in elderly Japanese men. Oncotarget. 2016; 7:44919 44926. https://doi.org/10.18632/oncotarget.10229.

13. Shi Q, Rafii S, Wu MH, Wijelath ES, Yu C, Ishida A, Fujita Y, Kothari S, Mohle R, Sauvage LR, Moore MA, Storb RF, Hammond WP. Evidence for circulating bone marrowderived endothelial cells. Blood. 1998; 92:362-367.

14. Guralnik JM, Ershler WB, Schrier SL, Picozzi VJ. Anemia in the elderly: a public health crisis in hematology. Hematology Am Soc Hematol Educ Program. 2005; 528532.

15. Shimizu Y, Nakazato M, Sekita T, Kadota K, Arima K, Yamasaki H, Takamura N, Aoyagi K, Maeda T. Association between the hemoglobin levels and hypertension in relation to the BMI status in a rural Japanese population: the Nagasaki Islands Study. Intern Med. 2014; 53:435-440.

16. Shimizu Y, Nakazato M, Sekita T, Kadota K, Yamasaki H, Takamura N, Aoyagi K, Maeda T. Association between hemoglobin levels and arterial stiffness for general Japanese population in relation to body mass index status: The Nagasaki Islands study. Geriatr Gerontol Int. 2014; 14:811818.

17. Shimizu Y, Kadota K, Nakazato M, Noguchi Y, Koyamatsu J, Yamanashi H, Nagayoshi M, Nagata S, Arima K, Maeda T. Hemoglobin as a possible biochemical index of hypertension-induced vascular damage. J Physiol Anthropol. 2016; 35:4.

18. Endemann DH, Schiffrin EL. Endothelial dysfunction. J Am Soc Nephrol. 2004; 15:1983-1992.

19. Chen J, López JA. Interactions of platelets with subendothelium and endothelium. Microcirculation. 2005; 12:235-246.

20. Nakamura T, Kambayashi J, Okuma M, Tandon NN. Activation of the GP IIb-IIIa complex induced by platelet adhesion to collagen is mediated by both alpha2beta1 integrin and GP VI. J Biol Chem. 1999; 274:11897-11903

21. Zaffran Y, Meyer SC, Negrescu E, Reddy KB, Fox JE. Signaling across the platelet adhesion receptor glycoprotein Ib-IX induces alpha IIbbeta 3 activation both in platelets and a transfected Chinese hamster ovary cell system. J Biol Chem. 2000; 275:16779-16787.

22. Ferroni P, Martini F, Riondino S, La Farina F, Magnapera A, Ciatti F, Guadagni F. Soluble P-selection as a marker of in vivo platelet activation. Clin Chim Acta. 2009; 399:88-91.

23. Takahashi T, Kalka C, Masuda H, Chen D, Silver M, Kearney M, Magner M, Isner JM, Asahara T. Ischemia- and cytokine-induced mobilization of bone marrow-derived endothelial progenitor cells for neovascularization. Nat Med. 1999; 5:434-438.
24. Zou J, Yuan C, Wu C, Cao C, Yang H. The effects of platelet-rich plasma on the osteogenic induction of bone marrow mesenchymal stem cells. Connect Tissue Res. 2014; 55:304-309.

25. Garvin K, Feschuk C, Sharp JG, Berger A. Does the number or quality of pluripotent bone marrow stem cells decrease with age? Clin Orthop Relat Res. 2007; 465:202-207.

26. Shimizu Y, Sato S, Koyamatsu J, Yamanashi H, Nagayoshi M, Kadota K, Kawashiri SY, Inoue K, Nagata Y, Maeda T. Platelets and circulating CD34-positive cells as an indicator of the activity of the vicious cycle between hypertension and endothelial dysfunction in elderly Japanese men. Atherosclerosis 2017; 259:26-31.

27. Shimizu Y, Sato S, Koyamatsu J, Yamanashi H, Nagayoshi M, Kadota K, Maeda T. Height indicates hematopoietic capacity in elderly Japanese men. Aging (Albany NY). 2016; 8:2407-2413. https://doi.org/10.18632/aging.101061.

28. Shimizu Y, Sato S, Koyamatsu J, Yamanashi H, Nagayoshi M, Kadota K, Maeda T. Height is an indicator of vascular maintenance capacity in older men. Geriatr Gerontol Int. 2016; [Epub ahead of print]

29. Matsubara Y, Ono Y, Suzuki H, Arai F, Suda T, Murata M, Ikeda Y. OP9 bone marrow stroma cells differentiate into megakaryocytes and platelets. PLoS One 2013; 8:e58123.

30. Nasto LA, Fusco A, Colangelo D, Mormando M, Di Giacomo G, Rossi B, De Marinis L, Logroscino CA, Pola E. Clinical predictors of vertebral osteoporotic fractures in post-menopausal women: a cross-sectional analysis. Eur Rev Med Pharmacol Sci. 2012; 16:1227-1234.

31. Asaoka D, Nagahara A, Shimada Y, Matsumoto K, Ueyama H, Matsumoto K, Nakagawa Y, Takeda T, Tanaka I, Sasaki H, Osada T, Hojo M, Watanabe S. Risk factors for osteoporosis in Japan: is it associated with Helicobacter pylori? Ther Clin Risk Manag. 2015; 11:381-391.

32. Shimizu Y, Nakazato M, Sekita T, Kadota K, Miura Y, Arima K, Yamasaki H, Goto H, Takamura N, Aoyagi K, Maeda T. Height and drinking status in relation to risk of anemia in rural adult healthy Japanese men: the Nagasaki Islands study. Aging Male. 2015; 18:100-105.

33. Engeland A, Bjørge T, Selmer RM, Tverdal A. Height and body mass index in relation to total mortality. Epidemiology. 2003; 14:293-299.

34. Sutherland DR, Anderson L, Keeney M, Nayar R, Chin-Yee I. The ISHAGE guidelines for CD34+ cell determination by flow cytometry. International Society of Hematotherapy and Graft Engineering. J Hematother. 1996; 5:213-226.

35. Hara T, Takamura N, Akashi S, Nakazato M, Maeda T, Wada M, Nakashima K, Abe Y, Kusano Y, Aoyagi K. Evaluation of clinical markers of atherosclerosis in young and elderly Japanese adults. Clin Chem Lab Med. 2006; 44:824-829. 